\title{
Adubação boratada e produção de sementes de trigo
}

\author{
Boron fertilization on wheat seed production
}

\begin{abstract}
André Pich Brunes ${ }^{I^{*}}$ Sandro de Oliveira ${ }^{\mathrm{I}}$ Elisa Souza Lemes ${ }^{\mathrm{I}}$ Lizandro Ciciliano Tavares $^{\mathrm{I}}$ Vânia Marques Gehling ${ }^{I}$ Letícia Winke Dias ${ }^{I}$ Francisco Amaral Villela ${ }^{I}$
\end{abstract}

\section{RESUMO}

$A$ deficiencia de $B$ pode diminuir a fertilidade das flores, prejudicando a produtividade de sementes de trigo. $O$ trabalho objetivou avaliar a produção e a qualidade fisiológica de sementes de trigo produzidas sobre épocas e doses de aplicação de B. $O$ experimento foi desenvolvido no laboratório didático de análise de sementes e em casa de vegetação, no município do Capão do Leão (RS). O delineamento experimental utilizado foi completamente casualizado, com quatro repetições e em esquema fatorial, envolvendo estádio de aplicação (semeadura e

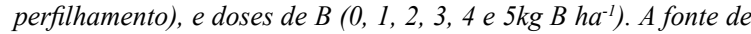
$B$ utilizada foi o tetraborato de sódio (boráx), o qual apresenta $11,5 \%$ de B. A adubação boratada, aplicada na semeadura ou perfilhamento, em doses entre $2,5 \mathrm{~kg}$ e $3 \mathrm{~kg}$ de $B \mathrm{ha}^{-1}$ ocasionam aumento no número de sementes e espigas produzidas por planta, redução do rendimento de sementes por planta, peso de mil sementes e o peso hectolitrico, sem causar redução na qualidade fisiológica de sementes de trigo. As plantas de trigo apresentam maior absorção de B na aplicação no estádio de perfilhamento, em relação à fase de semeadura.

Palavras-chave: Triticum aestivum L., boro, micronutriente, germinação, vigor.

\section{ABSTRACT}

Boron deficiency can decrease fertility of flowers, harming productivity of wheat seeds. The experiment was conducted in didactic laboratory seed testing and in the greenhouse, both located in the municipality of Capão do Leão (RS). The objective of this study was to evaluate the production and physiological quality of wheat seed produced on time and doses of B application. The experimental design was completely randomized, with four replications in a factorial arrangement involving application stage (seeding and tillering), and $B$ doses $\left(0,1,2,3,4\right.$ and $\left.5 \mathrm{~kg} \mathrm{ha}^{-1}\right)$. The B source utilized was sodium tetraborate (borax), which has $11.5 \%$ of $B$. Boron fertilization applied at sowing and tillering at doses

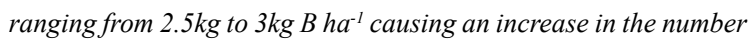
of seeds produced per plant and spikes, reduction of seed yield per plant, thousand seed weight and weight hectoliter, no reduction in physiological seed quality of wheat. Wheat plants have a higher absorption of $B$ application on the tillering stage in relation to the stage of sowing.

Key words: Triticum aestivum L., boron, micronutrient, germination, vigor.

\section{INTRODUÇÃO}

O trigo é o principal cereal de inverno produzido no Brasil, contribuindo significativamente para a economia do país. Na safra de 2012, apresentou uma produção média de 5,03 milhões de toneladas, sendo esta concentrada principalmente nos estados do Rio Grande do Sul (RS) e Paraná (PR), com 48 e $42 \%$ do total produzido no país, respectivamente (CONAB, 2013).

A produtividade do trigo varia anualmente e de região para região, por causa, principalmente, da deficiência nutricional, doenças, pragas e fertilidade do solo (TAVARES et al., 2013). Este último fator, torna-se ainda mais agravante no que tange à produção de sementes, pois as exigências nutricionais necessárias para obtenção de um produto de alta germinabilidade e vigor são maiores em relação à produção de grãos, especialmente em relação ao $\mathrm{B}$, que é um micronutriente essencial para a divisão celular e alongamento de tecidos meristemáticos e órgãos florais, fertilidade de flores masculinas, germinação e

'Departamento de Fitotecnia, Faculdade de Agronomia Eliseu Maciel (FAEM), Universidade Federal de Pelotas (UFPel), Av. Eliseu Maciel, s/n, 96001-970, Capão do Leão, RS, Brasil. E-mail: beldar_brunes@msn.com. *Autor para correspondência. 
alongamento do tubo polínico e formação de semente e frutos (FURLANI et al., 2003). Além disso, as sementes deficientes em $\mathrm{B}$ podem levar à incidência de plântulas anormais (MARSCHNER, 1995).

A deficiência de $\mathrm{B}$ ocasiona também reduções severas na produtividade das culturas e distúrbios em processos metabólicos dependentes deste elemento, bem como metabolismo de ácidos nucleicos, carboidratos, proteínas e ácido indol acético, síntese de parede celular, integridade e funcionamento da membrana celular e metabolismo de fenóis (TANAKA \& FUJIWAR, 2008; FAROOQ et al., 2012). Na cultura do trigo, esta deficiência foi identificada como a causa principal da esterilidade de flores (RERKASEM \& JAMJOD, 1989). A fertilidade masculina é afetada principalmente por prejudicar a microsporogênese e crescimento do tubo polínico e efeitos pós-fertilização, que incluem problemas na embriogênese, resultando em aborto da semente, formação de embriões incompletos ou danificados e frutos deformados (FURLANI et al., 2003). Ressalta-se que a tolerância a baixos níveis deste elemento no solo pode ser dependente da variabilidade genotípica da cultura.

Diante do exposto, o presente trabalho teve por objetivo avaliar a produção e a qualidade fisiológica de sementes de trigo produzidas sobre diferentes épocas e doses de aplicação de B.

\section{MATERIAL E MÉTODOS}

O experimento foi realizado durante o ano agrícola 2012/2013 no laboratório didático de análise de sementes e em casa de vegetação, ambos localizados no município do Capão do Leão (RS) (Latitude $31^{\circ} 48^{\prime} 02.69$ ' S). Utilizaram-se sementes de trigo, cultivar 'FUNDACEP Horizonte'.

O delineamento experimental utilizado foi completamente casualizado, com quatro repetições. Os tratamentos constaram de um esquema fatorial envolvendo estádio de aplicação (semeadura e perfilhamento) e doses de B (0, 1, 2, 3, 4 e $\left.5 \mathrm{~kg} \mathrm{~B} \mathrm{ha}^{-1}\right)$, aplicados via solo. A fonte de B utilizada foi o tetraborato de sódio (boráx), o qual apresenta $11,5 \%$ de $\mathrm{B}$.

$\mathrm{Na}$ semeadura, utilizaram-se vasos com capacidade de 8 litros preenchidos com $7 \mathrm{~kg}$ de solo peneirado, coletado de um horizonte A1 de um Planossolo Háplico eutrófico solódico (EMBRAPA, 2013), pertencente à unidade de mapeamento Pelotas (STRECK et al., 2008). O teor de B total foi de $7,25 \mathrm{mg} \mathrm{kg}^{-1}$. A adubação e a calagem foram realizadas de acordo com a análise de solo, seguindo as recomendações da CQFS-RS/SC (2004), nas doses de $2,7 \mathrm{t} \mathrm{ha}^{-1}$ de calcário, $80 \mathrm{~kg} \mathrm{ha}^{-1}$ de uréia, $50 \mathrm{~kg} \mathrm{ha}^{-1} \mathrm{de}$ $\mathrm{P}_{2} \mathrm{O}_{5}$ e $40 \mathrm{~kg} \mathrm{ha}^{-1}$ de $\mathrm{K}_{2} \mathrm{O}$, incorporando manualmente o corretivo ao solo aos 60 dias e os adubos 7 dias antes da semeadura.

Após emergência, foram mantidas quatro plantas por unidade experimental, sendo irrigadas diariamente até a capacidade de campo. A colheita foi realizada manualmente quando as sementes apresentavam $22 \%$ de umidade e, em seguida, avaliaram-se as seguintes variáveis: (i) número de espigas (NE) e (ii) número de sementes por planta (NSP), realizado por contagem manual das espigas e sementes em cada unidade experimental; (iii) massa de sementes por planta (MSP), obtida pela pesagem das sementes colhidas, sendo a umidade corrigida para 13\%; (iv) peso hectolítrico $(\mathrm{PH})$, realizada com quatro repetições e balança específica, com capacidade de 1L de sementes, sendo o resultado expresso em $\mathrm{kg} \mathrm{hL}^{-1} \mathrm{e}(\mathrm{v})$ peso de mil sementes (PMS), empregando-se oito repetições de 100 sementes. O PMS foi calculado a partir da média, o desvio padrão e o coeficiente de variação das pesagens. Como todas as parcelas apresentaram coeficiente de variação inferior a quatro, multiplicou-se a média por 10, e assim obteve-se o peso de mil sementes (BRASIL, 2009).

A qualidade fisiológica das sementes foi avaliada pelos seguintes testes: Teste de germinação (G), realizado com quatro amostras de 50 sementes para cada unidade experimental. A semeadura foi realizada em substrato de papel, previamente umedecido em água destilada, na proporção de 2,5 vezes o peso do papel seco e mantido em germinador à temperatura de $20^{\circ} \mathrm{C}$. As avaliações foram efetuadas aos oito dias após a semeadura, conforme as Regras para Análise de Sementes (BRASIL, 2009) e os resultados expressos em porcentagem de plântulas normais. A primeira contagem da germinação (PCG) foi avaliada aos quatro dias após a semeadura, por ocasião da realização do teste de germinação. $\mathrm{O}$ teste de frio (TF) foi conduzido com quatro amostras de 50 sementes para cada unidade experimental, sendo os rolos de papel colocados em sacos plásticos, os quais foram vedados e mantidos em câmara regulada à temperatura de $10^{\circ} \mathrm{C}$, durante sete dias. Após esse período, foram transferidas para um germinador e mantidas nas mesmas condições do teste de germinação (CÍCERO \& VIEIRA, 1994).

Para confirmação dos resultados obtidos nas demais avaliações, aferiu-se o teor de B nas folhas, imediatamente após a colheita, por meio do método da azometina-H em extrato obtido por digestão via seca (TEDESCO et al., 1995).

Ciência Rural, v.45, n.9, set, 2015. 
Os dados foram analisados quanto à normalidade e homocedasticidade e constatou não haver necessidade de transformação. Então foram submetidos à análise de variância e analisados por comparação de médias pelo teste $\mathrm{T}$ para estádio e regressão linear para as doses, todos a $5 \%$ de probabilidade. Para a análise estatística, foi utilizado o Sistema de Análise Estatística Winstat versão 1.0 (MACHADO \& CONCEIÇÃO, 2003).

\section{RESULTADOS E DISCUSSÃO}

$\mathrm{O}$ vigor, avaliado pelo teste de primeira contagem da germinação, diferiu em relação ao estádio de aplicação de B apenas na dose de $5 \mathrm{~kg} \mathrm{~B}$ $\mathrm{ha}^{-1}$, cuja aplicação no perfilhamento resultou em sementes menos vigorosas (Tabela 1). A aplicação de $\mathrm{B}$ na semeadura não apresentou comportamento que se ajustasse aos modelos de regressão testados, entretanto, efetuada no perfilhamento, houve um incremento no vigor das sementes produzidas até a dose de 2,15kg B ha-1 (Figura 1a). Em estudo semelhante, o tratamento de sementes de trigo com $\mathrm{Zn}, \mathrm{B}$ e Mo nas doses de 182,$4 ; 7,6$ e 45,6g L-1, respectivamente, prejudicou o vigor das sementes determinado através do teste de primeira contagem da germinação em relação àquelas tratadas apenas com $\mathrm{Zn}$, contudo, as sementes produzidas posteriormente, ou seja, através das plantas oriundas dos respectivos tratamentos, não apresentaram diferença nesta determinação (TAVAREZ et al., 2013).

Há muitos atributos para caracterizar a qualidade das sementes, mas os principais indicadores de qualidade são o tamanho e a eficiência (ZEČEVIĆ et al., 2006). A germinação das sementes produzidas, atributo fundamental para o estabelecimento da lavoura e, consequentemente, para a produção de grãos, não foi alterada pelas doses de $\mathrm{B}$ aplicadas em ambos os estádios de adubação (Tabela 1). Da mesma forma, o teste de frio, o qual avalia o vigor das sementes submetendo-as a condições de baixas temperaturas, apresentaram similaridade entre os tratamentos (Tabela 1).

A adubação boratada na fase de perfilhamento acarretou maior número de espigas produzidas apenas na dose de $3 \mathrm{~kg} \mathrm{~B} \mathrm{ha-1}$. Para as demais doses, não houve diferença entre os estádios de aplicação nesta variável (Tabela 1). Em ambos os estádios de aplicação, o aumento da dose de B resultou em comportamento quadrático, cujas doses

Tabela 1 - Primeira contagem da germinação (PCG), germinação $(\mathrm{G})$ e teste de frio (TF), número de espigas por planta, número de sementes por planta e massa de sementes por planta de trigo, cultivar 'FUNDACEP Horizonte', produzidas com diferentes doses de adubação boratada, aplicadas na semeadura (S) ou perfilhamento (P).

\begin{tabular}{|c|c|c|c|c|c|c|}
\hline \multirow{2}{*}{ Dose de B $\left(\mathrm{kg} \mathrm{ha}^{-1}\right)$} & \multicolumn{2}{|c|}{ 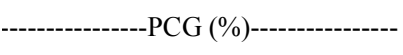 } & \multicolumn{2}{|c|}{----------------G (\%)---------------- } & \multicolumn{2}{|c|}{ 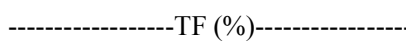 } \\
\hline & Semeadura & Perfilhamento & Semeadura & Perfilhamento & Semeadura & perfilhamento \\
\hline 0 & $93 \mathrm{a}^{1}$ & $93 \mathrm{a}$ & 99 & 99 & 91 & 91 \\
\hline 1 & $95 \mathrm{a}$ & $98 \mathrm{a}$ & 100 & 100 & 90 & 92 \\
\hline 2 & $96 \mathrm{a}$ & $95 \mathrm{a}$ & 99 & 99 & 92 & 92 \\
\hline 3 & $93 \mathrm{a}$ & $95 \mathrm{a}$ & 99 & 99 & 92 & 93 \\
\hline 4 & $95 \mathrm{a}$ & $94 \mathrm{a}$ & 100 & 99 & 93 & 93 \\
\hline 5 & $97 \mathrm{a}$ & $90 \mathrm{~b}$ & 100 & 100 & 90 & 91 \\
\hline Média & 95 & 94 & $99 \mathrm{a}$ & $99 \mathrm{a}$ & $91 \mathrm{a}$ & $92 \mathrm{a}$ \\
\hline $\mathrm{CV}(\%)$ & \multicolumn{2}{|c|}{2,75} & \multicolumn{2}{|c|}{1,22} & \multicolumn{2}{|c|}{4,63} \\
\hline \multirow{2}{*}{ Dose de B $\left(\mathrm{kg} \mathrm{ha}^{-1}\right)$} & \multicolumn{2}{|c|}{--------No espigas planta ${ }^{-1}$} & \multicolumn{2}{|c|}{---------No Sementes planta--------- } & \multicolumn{2}{|c|}{------Massa sementes planta (g) ----- } \\
\hline & Semeadura & Perfilhamento & Semeadura & Perfilhamento & Semeadura & Perfilhamento \\
\hline 0 & $6,69 \mathrm{a}^{1}$ & $6,69 \mathrm{a}$ & 301,13 & 301,13 & 14,09 & 14,10 \\
\hline 1 & $7,94 \mathrm{a}$ & $7,25 \mathrm{a}$ & 376,15 & 354,54 & 15,08 & 12,68 \\
\hline 2 & $7,94 \mathrm{a}$ & $7,88 \mathrm{a}$ & 368,95 & 390,08 & 14,34 & 12,55 \\
\hline 3 & $7,56 \mathrm{~b}$ & $8,75 \mathrm{a}$ & 361,79 & 358,46 & 11,86 & 12,76 \\
\hline 4 & $7,59 \mathrm{a}$ & $7,42 \mathrm{a}$ & 348,20 & 343,17 & 12,02 & 12,11 \\
\hline 5 & $7,33 \mathrm{a}$ & $7,31 \mathrm{a}$ & 303,83 & 328,84 & 11,22 & 10,82 \\
\hline Média & 7,51 & 7,55 & $343,34 \mathrm{a}$ & $346,04 \mathrm{a}$ & $11,22 \mathrm{a}$ & $12,51 \mathrm{a}$ \\
\hline C.V. $(\%)$ & \multicolumn{2}{|c|}{6,90} & \multicolumn{2}{|c|}{7,85} & \multicolumn{2}{|c|}{9,42} \\
\hline
\end{tabular}

${ }^{1}$ Médias seguidas da mesma letra na linha, para cada variável, não diferem entre si pelo teste $\mathrm{T}(\mathrm{p}=0,05)$. 
de máxima eficiência foram de 2,68 e $2,82 \mathrm{~kg} \mathrm{~B} \mathrm{ha}^{-1}$ para semeadura e perfilhamento, respectivamente. Nessas doses, houve aumento médio de uma espiga por planta, para a adubação realizada na semeadura, e cerca de 1,5 espigas no perfilhamento (Figura 1b).

Houve semelhança entre os estádios de adubação boratada no número de sementes por planta (Tabela 1), contudo, o aumento da dose resultou em comportamento quadrático, cuja dose de $2,49 \mathrm{~kg} \mathrm{~B}$ $\mathrm{ha}^{-1}$ apresentou máxima eficiência, resultando em uma produção de 64,5 sementes por planta, maior do que a dose zero (Figura 1c). Os resultados contrastam com pesquisa anterior, onde plantas de trigo cultivadas em solução nutritiva com diferentes doses de ácido bórico $\left(0,0 ; 0,05 ; 0,2 ; 0,8\right.$ e $\left.2,0 \mathrm{mg} \mathrm{B} \mathrm{L}^{-1}\right)$ diferiram no número de sementes por espiga e no número de sementes por planta apenas na ausência do micronutriente, onde não houve produção (FURLANI et al., 2003).

A massa de sementes por planta não diferiu entre os dois estádios de aplicação (Tabela 1). Contrariamente ao número de espigas por planta e número de sementes por planta, a massa de sementes por planta reduziu linearmente com aumento da dose de B aplicada na adubação, esta redução média foi de $0,63 \mathrm{~g}$ de sementes por planta para cada $1 \mathrm{~kg}$ B ha $^{-1}$ (Figura 1d). Diferindo do resultado encontrado

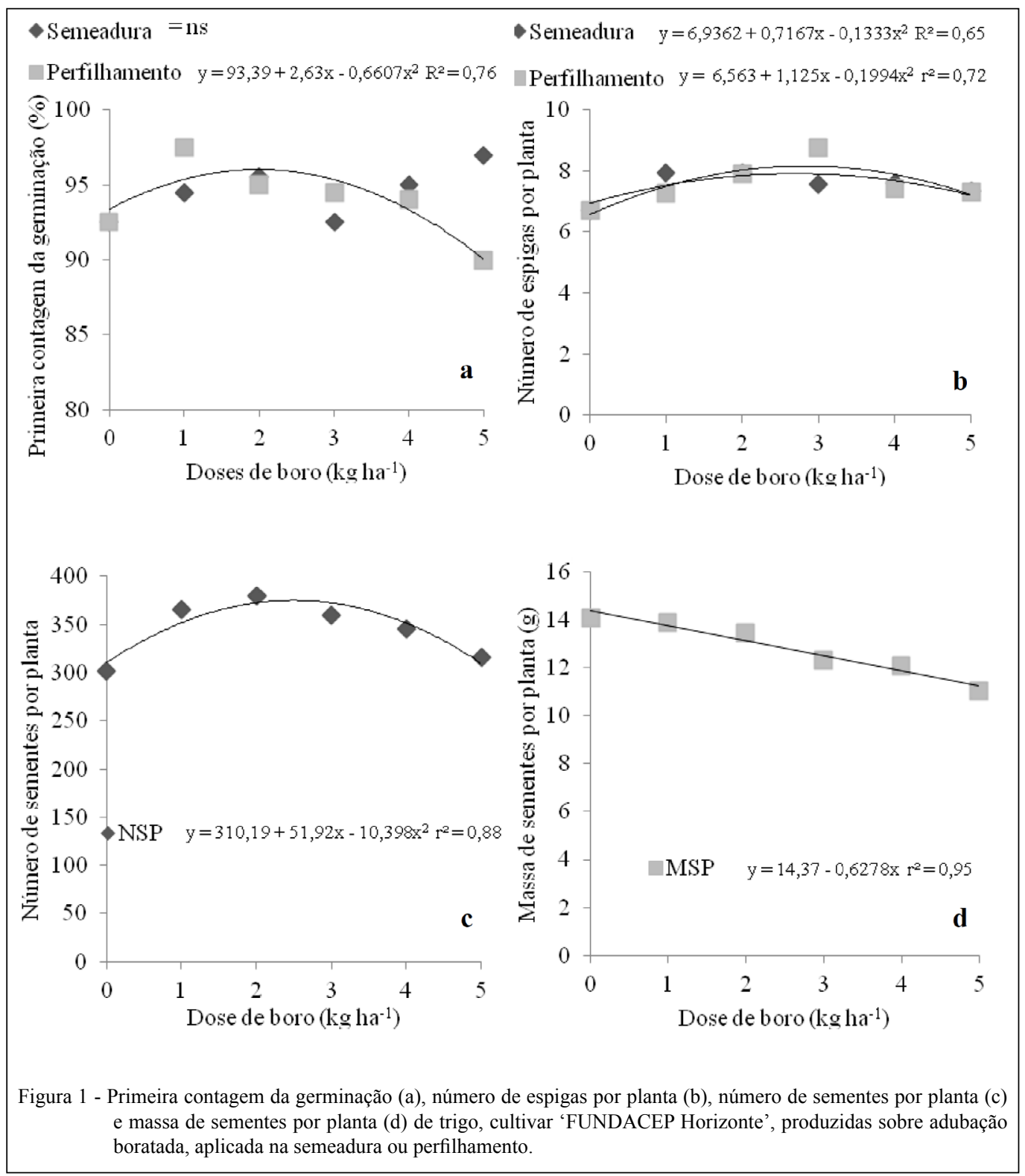

Ciência Rural, v.45, n.9, set, 2015. 
na presente pesquisa, a aplicação foliar de B (100g $\left.\mathrm{L}^{-1}\right)$ na antese apresentou rendimento superior a $646 \mathrm{~kg} \mathrm{ha}^{-1}$ em relação ao tratamento sem aplicação de B (TAHIR et al., 2009). Esse resultado negativo no rendimento pode estar relacionado à baixa demanda deste nutriente nos estádios iniciais da cultura, em que foram realizadas as aplicações, pois as poáceas apresentam menor requerimento de B para manter um crescimento vegetativo normal, mas precisam tanto deste elemento quanto outras espécies no estádio reprodutivo (BLEVINS \& LUKASZEWSKI, 1998). Consta na literatura que o teor crítico de B na parte aérea das plantas durante os estádios iniciais de elongação da cultura compreende valores entre 2,5 e 6,0 $\mathrm{mg} \mathrm{kg}^{-1}$ (BERGMANN, 1992).

O peso de mil sementes, de modo geral, foi superior para a adubação boratada realizada na semeadura, sendo superior em três das cinco doses de B aplicadas (Tabela 2). A aplicação do micronutriente reduziu linearmente o peso de mil sementes, tanto na aplicação na semeadura, cuja redução foi de $0,90 \mathrm{~g}$ em mil sementes por $\mathrm{kg}$ de B aplicado por hectare, quanto no perfilhamento, cuja redução foi de 1,26g por mil sementes (Figura 2a). Os resultados discordam dos encontrados em estudo conduzido em solo de várzea no Antigo
Brahmaputra, onde a aplicação nas doses entre 0,75 e $3,0 \mathrm{~kg} \mathrm{~B} \mathrm{ha}^{-1}$ não alteraram o peso de mil sementes da cultura, e aumentou o rendimento de grãos até a dose de 1,9kg B ha-1 (DEBNATH et al., 2011). Contudo, na presente pesquisa, a redução do peso de mil sementes pode estar relacionada com o maior número de sementes produzidas por planta, havendo uma compensação na distribuição das reservas que resultou em sementes de menor massa.

O peso hectolítrico diferiu em relação aos estádios de adubação apenas na dose de $5 \mathrm{~kg}$ $\mathrm{B} \mathrm{ha}{ }^{-1}$, que foi inferior na aplicação efetuada no perfilhamento (Tabela 2). Para esta mesma variável, a adubação na semeadura resultou em comportamento quadrático, decrescendo o peso de sementes por hectolitro até a dose de $2,74 \mathrm{~kg} \mathrm{~B} \mathrm{ha}^{-1}$. Contrariamente, a incorporação desse elemento no perfilhamento resultou em comportamento quadrático positivo, cuja dose de máxima eficiência foi de $0,84 \mathrm{~kg} \mathrm{~B} \mathrm{ha}^{-1}$ (Figura 2b). O B atua na translocação de açúcares para os órgãos propagativos, contudo, o nível tóxico de $\mathrm{B}$ no solo e nas plantas está bastante próximo aos níveis de deficiência, o que pode explicar o comportamento quadrático verificado no presente trabalho (BERNSTEIN \& HAYWARD, 1958; MALAVOLTA et al., 2002).

Tabela 2- Peso de mil sementes e peso hectolítrico de sementes de trigo e teor de B nas folhas de trigo, cultivar 'FUNDACEP Horizonte', produzidas sobre diferentes doses de adubação boratada, aplicadas na semeadura (S) ou perfilhamento (P).

\begin{tabular}{|c|c|c|c|c|}
\hline \multirow{2}{*}{ Dose de B $\left(\mathrm{kg} \mathrm{ha}^{-1}\right)$} & \multicolumn{2}{|c|}{--------------Peso de mil sementes (g) ---------------- } & \multicolumn{2}{|c|}{--------------Peso hectolítrico $\left(\mathrm{g} \mathrm{hL}^{-1}\right)$-------------- } \\
\hline & Semeadura & Perfilhamento & Semeadura & Perfilhamento \\
\hline 0 & $44,43 \mathrm{a}^{1}$ & $44,43 \mathrm{a}$ & $78,70 \mathrm{a}$ & $78,70 \mathrm{a}$ \\
\hline 1 & $44,02 \mathrm{a}$ & $43,39 \mathrm{a}$ & $77,15 \mathrm{a}$ & $76,90 \mathrm{a}$ \\
\hline 2 & $44,84 \mathrm{a}$ & $43,39 \mathrm{~b}$ & $77,41 \mathrm{a}$ & $77,18 \mathrm{a}$ \\
\hline 3 & $41,28 \mathrm{a}$ & $41,72 \mathrm{a}$ & $77,14 \mathrm{a}$ & $77,41 \mathrm{a}$ \\
\hline 4 & $41,97 \mathrm{a}$ & $40,67 \mathrm{~b}$ & $77,82 \mathrm{a}$ & $77,41 \mathrm{a}$ \\
\hline 5 & $40,09 \mathrm{a}$ & $37,56 \mathrm{~b}$ & $77,79 \mathrm{a}$ & $75,24 \mathrm{~b}$ \\
\hline Média & 42,77 & 41,86 & 77,67 & 77,14 \\
\hline C.V. $(\%)$ & \multicolumn{2}{|c|}{2,59} & \multicolumn{2}{|c|}{0,74} \\
\hline \multirow{2}{*}{ Dose de B (kg ha-1) } & & \multicolumn{3}{|c|}{---------------------------Teor de B nas folhas $\left(\mathrm{mg} \mathrm{kg}^{-1}\right)$--------------------------- } \\
\hline & & \multicolumn{2}{|c|}{ Semeadura } & Perfilhamento \\
\hline \multicolumn{2}{|l|}{0} & \multicolumn{2}{|c|}{$80,25 \mathrm{a}^{1}$} & $80,25 \mathrm{a}$ \\
\hline \multicolumn{2}{|l|}{1} & \multicolumn{2}{|c|}{$108,50 \mathrm{~b}$} & $172,75 \mathrm{a}$ \\
\hline \multicolumn{2}{|l|}{2} & \multicolumn{2}{|c|}{$151,25 \mathrm{~b}$} & $212,75 \mathrm{a}$ \\
\hline \multicolumn{2}{|l|}{3} & \multicolumn{2}{|c|}{$155,00 \mathrm{~b}$} & $273,25 \mathrm{a}$ \\
\hline \multicolumn{2}{|l|}{4} & \multicolumn{2}{|c|}{$209,00 \mathrm{~b}$} & $332,25 \mathrm{a}$ \\
\hline \multicolumn{2}{|l|}{5} & \multicolumn{2}{|c|}{$216,00 \mathrm{~b}$} & $351,50 \mathrm{a}$ \\
\hline \multicolumn{2}{|l|}{ Média } & \multicolumn{2}{|c|}{153,33} & 237,13 \\
\hline C.V. $(\%)$ & & & 6,61 & \\
\hline
\end{tabular}

${ }^{1}$ Médias seguidas da mesma letra na linha não diferem entre si pelo teste $T(p=0,05)$. 


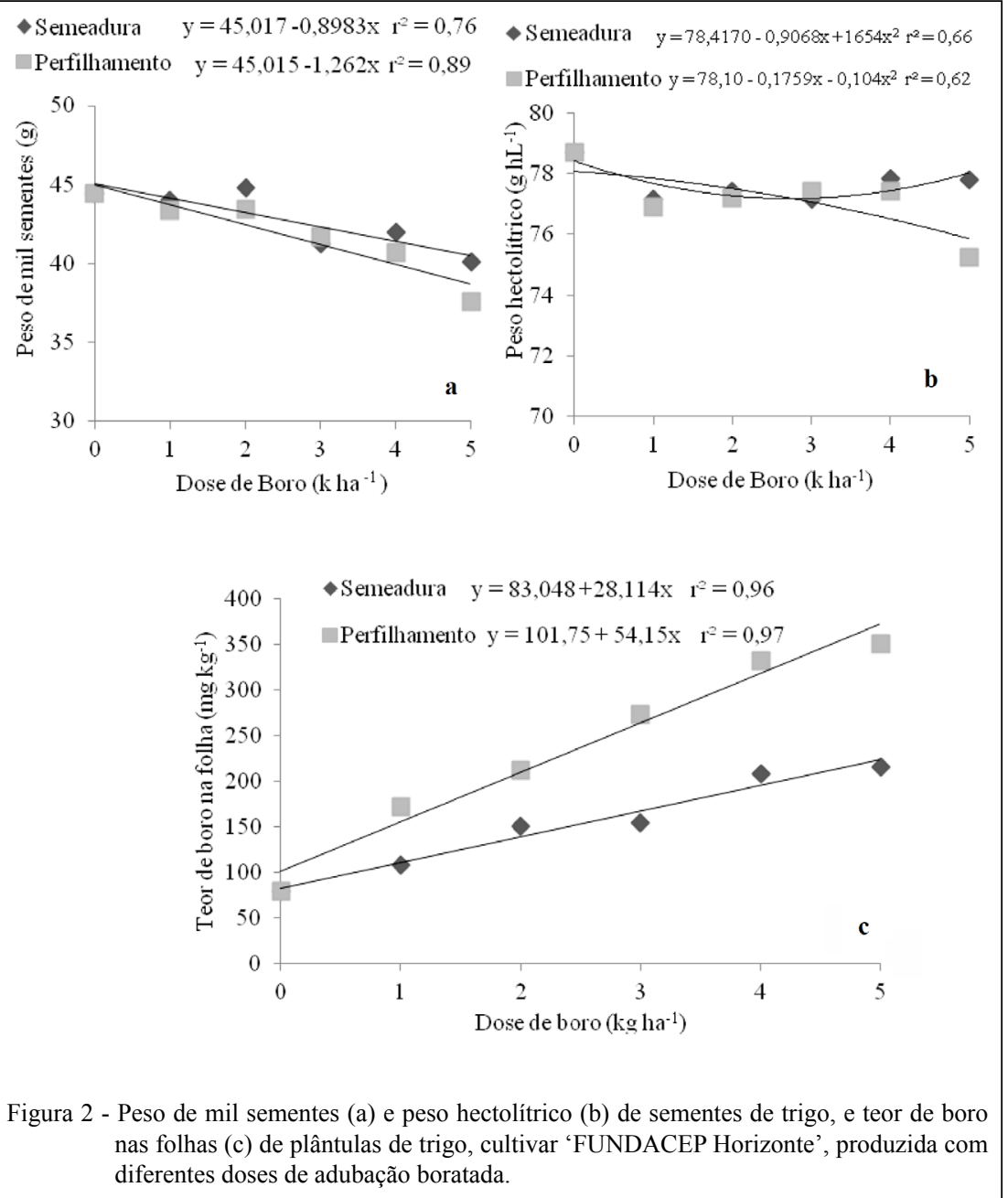

Em todas as doses estudadas, o teor de $\mathrm{B}$ nas folhas coletadas imediatamente após a colheita foi superior na aplicação no estádio de perfilhamento (Tabela 2). À medida que aumentou a dose de B, houve um incremento de $28,1 \mathrm{~g}$ e $54,2 \mathrm{~g} \mathrm{~kg}^{-1}$ de massa seca da folha, para semeadura e perfilhamento, respectivamente (Figura 2c). Foi constatado anteriormente que o nível crítico de deficiência de B para as cultivares 'IAC 24', 'IAC 60', 'IAC 287' e 'IAC 289 foi de $25 \mathrm{mg}$ $\mathrm{kg}^{-1}$ na matéria seca das folhas, e o nível crítico de toxicidade B variou 44 e $45 \mathrm{mg} \mathrm{kg}^{-1}$ para as cultivares 'IAC 60' e 'IAC 289'; 228 e $318 \mathrm{mg}$ $\mathrm{kg}^{-1}$ para as cultivares 'IAC 24' e 'IAC 287', respectivamente (FURLANI et al., 2003).

Apesar da adubação até doses entre 2,5 e $3,0 \mathrm{~kg} \mathrm{~B} \mathrm{ha-1}$ propiciar maior número de espigas por planta e consequentemente maior número de sementes produzidas por planta, estas apresentaram massa inferior às oriundas da dose zero, constatado pela menor massa de sementes por planta, menor peso de mil sementes e, em certas doses, menor peso hectolítrico. Em relação à qualidade fisiológica, a germinação não foi afetada nas sementes produzidas e verificou-se que o vigor pode ser acrescido na dose de $2,15 \mathrm{~kg}$ de $\mathrm{B} \mathrm{ha} \mathrm{h}^{-1}$ aplicada no perfilhamento. Esta dose correspondeu a um acúmulo de $\mathrm{B}$ nas folhas de aproximadamente $218 \mathrm{~g}$ do elemento $\mathrm{kg}^{-1}$ de massa seca. O aumento linear do teor de $\mathrm{B}$ nas folhas evidencia a influência desse elemento nos resultados observados neste trabalho.

\section{CONCLUSÃO}

A adubação boratada, aplicada na semeadura ou perfilhamento, em doses entre 2,5 e $3,0 \mathrm{~kg} \mathrm{~B} \mathrm{ha-1} \mathrm{ocasionaram} \mathrm{aumento} \mathrm{no} \mathrm{número} \mathrm{de}$ sementes e espigas produzidas por planta, redução

Ciência Rural, v.45, n.9, set, 2015. 
do rendimento de sementes por planta, peso de mil sementes e o peso hectolítrico, sem causar redução na qualidade fisiológica de sementes de trigo.

As plantas de trigo apresentam maior absorção de B na aplicação no estádio de perfilhamento em relação à fase de semeadura.

\section{AGRADECIMENTOS}

Os autores agradecem ao Conselho Nacional de Pesquisa e Desenvolvimento Tecnológico (CNPq), e a Coordenação de Aperfeiçoamento Pessoal de Nível Superior (CAPES), pelo financiamento da presente pesquisa através da concessão de bolsas de pós graduação.

\section{REFERÊNCIAS}

BERGMANN, W. Nutritional disorders of plants - development, visual and analytical diagnosis. Jena, Stuttgart, New York: Gustav Fischer Verlag, 1992. p.343-361.

BERNSTEIN, L.; HAYWARD, H.E. Physiology of salt tolerance. Annual review of plant physiology, v.9, p.25-46, 1958.

BLEVINS, D.G.; LUKASZEWSKI, K.M. Bn in plant structure and function. Annual Reviews. Plant Physiology Molecular Biology, v.49, p.48-500, 1998. Disponível em: $<$ http://www.annualreviews.org/doi/pdf/10.1146/annurev. arplant.49.1.481>. Acesso em: $19 \mathrm{dez} .2013$. doi: 10.1146/ annurev.arplant.49.1.481.

BRASIL. Ministério da Agricultura, Pecuária e Abastecimento. Regras para análise de sementes. Ministério da Agricultura, Pecuária e Abastecimento. Secretaria de Defesa Agropecuária. Brasília, DF: Mapa/ACS, 2009. 395p.

CÍCERO, S.M.; VIEIRA, R.D. Teste de frio. In: VIEIRA, R.D.; CARVALHO, N.M. (Ed.). Testes de vigor em sementes. Jaboticabal: FUNEP, 1994. p.151-164.

COMISSÃO DE QUÍMICA E FERTILIDADE DO SOLO - RS/ SC. Manual de adubação e de calagem para os Estados do Rio Grande do Sul e de Santa Catarina. 10.ed. Porto Alegre: NRS/ SBCS, 2004. 400p.

CONAB (COMPANHIA NACIONAL DE ABASTECIMENTO). Acompanhamento da safra brasileira de grãos, Safra 2011/2012: oitavo Levantamento - Maio/2013. Disponível em: $<$ http://www. conab.gov.br/OlalaCMS/uploads/arquivos/12_05_10_08_49_52_ boletim_maio_2012.pdf>. Acesso em: 20 abr. 2013.

DEBNATH, M.R. et al. Determining optimum rate of $\mathrm{Bn}$ application for higher yield of wheat in Old Brahmaputra floodplains soil. Journal of the Bangladesh Agricultural University, v.9, n.2, p.205-210, 2011. Disponível em: <http:// www.banglajol.info/index.php/JBAU/article/view/10987/8035>. Acesso em: 19 dez. 2013. doi: 10.3329/jbau.v9i2.10987.
EMPRESA BRASILEIRA DE PESQUISA AGROPECUÁRIA (EMBRAPA). Centro Nacional de Pesquisa de Solos. Sistema brasileiro de classificação de solos. 3.ed. Brasília, 2013. 353p.

FAROOQ, M. et al. Micronutrient application through seed treatments - a review. Journal of Soil Science and Plant Nutrition, v.12, n.1, p.125-142, 2012. Disponível em: $<$ http://www.scielo.cl/pdf/jsspn/v12n1/art11.pdf $>$. Acesso em: 19 dez. 2013. doi: 10.4067/S0718-95162012000100011.

FURLANI, A.M.C. et al. Wheat cultivar tolerance to Bn deficiency and toxicity in nutrient solution. Scientia Agricola, v.60, n.2, p.359-370, 2003. Disponível em: <http://www.scielo.br/pdf/ sa/v60n2/15340.pdf $>$. Acesso em: 19 dez. 2013. doi: 10.1590/ S0103-90162003000200022.

MACHADO, A.A.; CONCEIÇÃO, A.R. Sistema de análise estatística para Windows. UFPel, 2003. Winstat.Versão 1.0.

MALAVOLTA, E. et al. Adubos e adubações. São Paulo: Nobel, 2002. 200p.

MARSCHNER, H. Mineral nutrition of higher plants. 2.ed. New York: Academic, 1995. 889p.

RERKASEM, B.; JAMJOD, S. Correcting Bn deficiency indeced ear sterility in wheat and barley. Euphytica, v.96, n.2, p.257262, 1989. Disponível em: <http://download.springer.com/static/ pdf/723/art\%253A10.1023\%252FA\%253A1003093532561. pdf?auth66=1387634876_d9060130d5f8deb8b3e6699fddd4823f\& ext=.pdf $>$. Acesso em: 19 dez. 2013. doi: 10.1023/A:1003093532561.

STRECK, E.V. et al. Solos do Rio Grande do Sul. 2.ed. Porto Alegre: EMATER/RS-ASCAR, 2008. 222p.

TAHIR, M. et al. Yield response of wheat (Triticum aestivum L.) to Bn application at different growth stages. Pakistan Journal of Life and Social Sciences, v.7, n.1, p.39-42, 2009. Disponível em: $<$ http://pjlss.edu.pk/sites/default/files/8-tahir2-agron\%2039-42. pdf $>$. Acesso em: 19 dez. 2013.

TANAKA, M.; FUJIWAR, T. Physiological roles and transport mechanisms of Bn: perspectives from plants. Pflügers Arch European Journal of Physiology, v. 456, p.671-677, 2008. Disponível em: $<$ http://link.springer.com/article/10.1007/s00424-007-0370-8\#page-1>. Acesso em: 5 mai. 2015. doi: 0.1007/s00424-007-0370-8.

TAVARES, L.C. et al. Physiological performance of wheat seeds coated with micronutrients. Journal of Seed Science, v.35, n.1, p.2834, 2013. Disponível em: <http://www.scielo.br/pdf/jss/v35n1/04. pdf>. Acesso em: 19 dez. 2013. doi: 10.1007/s00424-007-0370-8.

TEDESCO MJ. et al. Análise de solo, planta e outros materiais. Porto Alegre: Departamento de Solo. Faculdade de Agronomia. Universidade do Rio Grande do Sul, 1995. 174p.

ZEČEVIĆ, V. et al. Influence of seed maturity on early seedling vigor in wheat. Kragujevac Journal of Science, v.28, n.1 p.165171, 2006. Disponível em: <http://www.pmf.kg.ac.rs/KJS/volumes/ kjs28/kjs28zecevicknezevic165.pdf>. Acesso em: 19 dez. 2013. 